\title{
Machinability, Hardness and Impact Behavior of Hybrid Fiber Reinforced Composites
}

\author{
Suresha K V, Shivanand H K, Srinivas K,Vignesh M, Swaroop
}

\begin{abstract}
Hybrid fabrics are represented by their excellent mechanical and structural properties as compared to conventional metals, which results in their increased functions especially for structural, aerospace applications, automotive, defense as well as sporting industries. In this paper the hybrid fabric (Jute, glass, carbon, Kevlar) composites are prepared by hand layup method and then vacuum bagging is used to avoid voids. The hardness, impact and machinablity test are performed by Rockwell hardness testing machine, Impact testing machine and Drill tool dynamometer respectively. From the results it has been observed that different parameter affects the hardness, toughness and machining of composites
\end{abstract}

Keywords : Hardness, Machinablity, Impact strength, Jute fabric, Hemp fabric, Kevlar fabric.

\section{INTRODUCTION}

Hybrid fiber reinforced composite material plays vital function in all fields [1]. The reinforcement of composites makes a decision of uniqueness of the material. Synthetic fabric reinforced composites in comparison with natural reinforced fabric, possesses high structural and mechanical properties. The clarification for this problem is to use combination of natural fabric and synthetic fabric. Hybridization helps to enhance the overall mechanical properties of the material. Natural hybrid fabric, which includes two relatively thin and stiff faces bonded to a low density core, offer many gains such as high tensile strength and hardness, excellent thermal and acoustic insulation properties, and high specific energy absorption. Due to escalating global contest, a number of industries have a sturdy need to establish an superior hybrid fabric for light weight, with appreciably higher tensile strength and bending stiffness.

\section{MATERIAL USED}

Many novel research works have been found on natural fibers and synthetic fibers composites. It has been found that the mechanical properties like Tensile, compression, flexural strength depends on the reinforcement and fabrication method. Jute/Jute/Kevlar fibers have found better properties in military and automobile applications [2].

Manuscript received on January 27, 2021

Revised Manuscript received on February 22, 2021.

Manuscript published on February 28, 2021

* Correspondence Author

Suresha K V*, Department of Mechanical Engineering, Don Bosco Institute of Technology, Bangalore, India. Email: kvsdbit@gmail.com

Shivanand H K , Department of Mechanical Engineering, UVCE,

Bangalore Bangalore, India. Email: shivanand.uvce@gmail.com

Srinivas K, Department of Mechanical Engineering, Don Bosco Institute of Technology, Bangalore, India.

Vignesh M, Department of Mechanical Engineering, Don Bosco Institute of Technology, Bangalore, India.

Swaroop, Department of Mechanical Engineering, Don Bosco Institute of Technology, Bangalore, India.
- Fabrication of laminates

Test laminates of composites $300 \mathrm{~mm} \times 300 \mathrm{~mm}$ were made-up to arrange experiment specimens by Hand lay-up process followed by Vacuum bag method to avoid air gap between the laminates.

\begin{tabular}{|c|c|}
\hline Reinforcement & $\begin{array}{l}\text { Jute fabric 500gsm, E glass fabric } \\
\text { 200gsm, carbon fabric 200gsm \& } \\
\text { Kevlar fabric200gsm. }\end{array}$ \\
\hline $\begin{array}{c}\text { Matrix: } \\
\text { Reinforcement ratio }\end{array}$ & $35: 65$ \\
\hline Molding method & $\begin{array}{c}\text { Hand lay-up followed by Vacuum } \\
\text { bagging }\end{array}$ \\
\hline Matrix Material & $\begin{array}{c}\text { Epoxy Resin (lapox L-12 Atul ltd) \& } \\
\text { Hardener K-6. }\end{array}$ \\
\hline
\end{tabular}

- Hardener and resin System Preparation

Hardener and resign were varied in a ratio of $1: 10$ by volume.

- Reinforcing material Preparation

The fabric used was Jute fabric of $500 \mathrm{gsm}$, E glass fabric $200 \mathrm{gsm}$, carbon fabric $200 \mathrm{gsm} \&$ Kevlar fabric $200 \mathrm{gsm}$ in the structure. The fabric structure is spread over plane surface and required dimension of $300 \mathrm{~mm} \mathrm{x} 300 \mathrm{~mm}$ is cut manually. Necessary layer of material be slice to obtain the necessary laminates thickness.

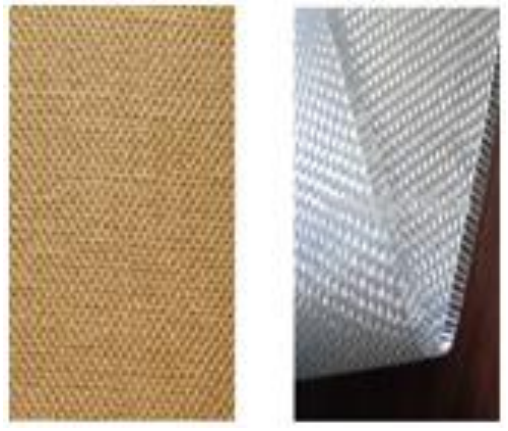

Fig 1: Jute fabric plain view 500gsm and E-Glass Fabric 200gsm
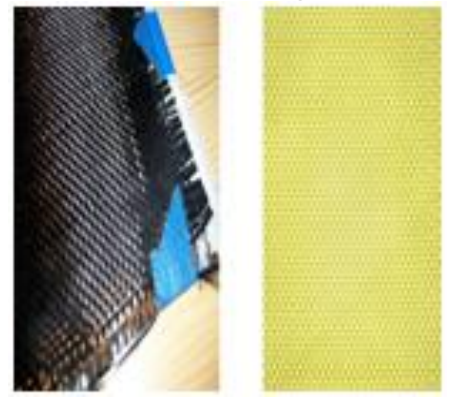

Fig 2: Carbon Fabric 200gsm and Kevlar Fabric 200gsm

- Number of layers of fabric for the composite laminates 
Machinability, Hardness and Impact Behavior of Hybrid Fiber Reinforced Composites

Table 1: Matrix and reinforcement properties

\begin{tabular}{|c|c|c|c|c|}
\hline Materials & $\begin{array}{c}\text { Density } \\
\text { gm./cc }\end{array}$ & $\begin{array}{c}\text { Volume } \\
\text { Fraction } \\
(\%)\end{array}$ & $\begin{array}{c}\text { Tensile } \\
\text { Strength } \\
\text { in MPa }\end{array}$ & $\begin{array}{c}\text { Young's } \\
\text { Modulus } \\
\text { in GPa }\end{array}$ \\
\hline Jute fiber & 1.46 & 0.275 & 270 & 76 \\
\hline $\begin{array}{c}\text { Kevlar } \\
\text { fiber }\end{array}$ & 1.44 & 0.275 & 3620 & 6 \\
\hline Glass fiber & 2.66 & 0.275 & 2000 & 72 \\
\hline $\begin{array}{c}\text { Carbon } \\
\text { fiber }\end{array}$ & 1.8 & 0.275 & 4500 & 228 \\
\hline Epoxy & 1.2 & 0.45 & 85 & 3.4 \\
\hline
\end{tabular}

- Number of layers for each laminates:

Jute-Carbon-Epoxy for $3 \mathrm{~mm}$ thick laminates $=7$ layer Jute-E-Glass-Epoxy laminate for $3 \mathrm{~mm}$ laminates $=7$ layer Jute-Kevlar-Epoxy laminate for $3 \mathrm{~mm}$ laminates $=7$ layer

- Laminate preparation by using Hand layup process (Unidirectional Specimen orientation)

- Vacuum bag method

To abolish air gap sandwiched stuck between layer of every fabric the vacuum bag method is enforced to the mould box, thereby increasing the strength between layers of the laminates and enhancing the properties of the material.

\section{- Curing of Laminates and specimen preparation}

Curing of laminates is a process used for complement the properties of the composite laminates. The post curing is essential to raise the glass transition temperature $(\mathrm{Tg})$ of the cured composite laminate. Water jet cutting is used to cut the specimen as per ASTM standard
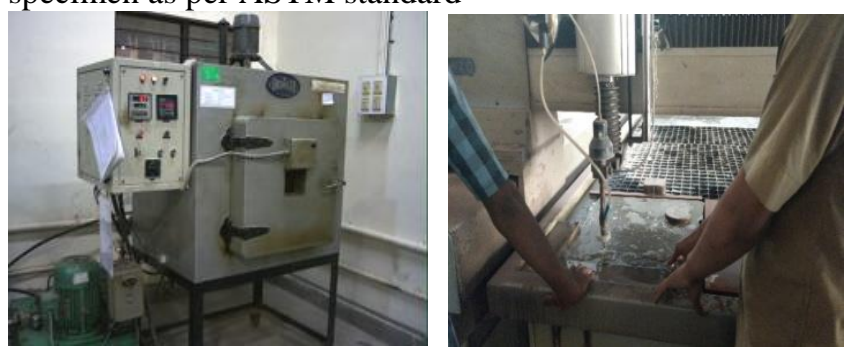

Fig 3: Post curing and specimen preparation

- Preparation of Hardness test, Impact test and, Machinability test specimen as per ASTM -E18, ASTM-D256, and ASTM-D4065 standards respectively for unidirectional laminates [3].

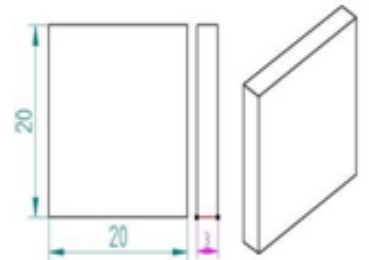

Fig 4(i)

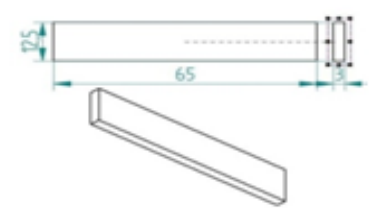

Fig 4(i)

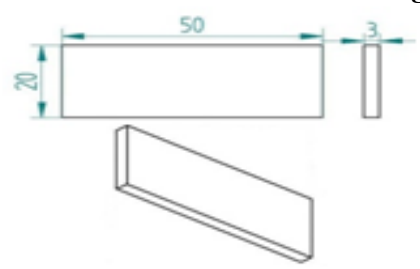

Fig 4(iii)

Fig 4(i,ii,iii) : .Geometry, Dimension of composite specimen for hardness, impact and Machinability test before and after testing

\section{RESULTS AND DISCUSSION}

3.1. Comparison of Hardness experiment Results of Jute-Glass-Epoxy, Jute-Kevlar-Epoxy and Jute-Carbon-Epoxy laminate composites

Table 2: Tabulation of Hardness Test Results

\begin{tabular}{|c|c|c|c|c|}
\hline $\begin{array}{c}\text { Sl. } \\
\text { No }\end{array}$ & Material & Trails & RHN & $\begin{array}{c}\text { Average } \\
\text { RHN }\end{array}$ \\
\hline & & 1 & 57 & \\
& & 2 & 52 & 50 \\
1 & J/G/E & 3 & 43 & \\
\hline & & 1 & 57 & \\
& & 2 & 59 & 53 \\
2 & & 3 & 43 & \\
\hline & & 1 & 88 & \\
& & 2 & 92 & 89 \\
3 & & 3 & 88 & \\
\hline
\end{tabular}

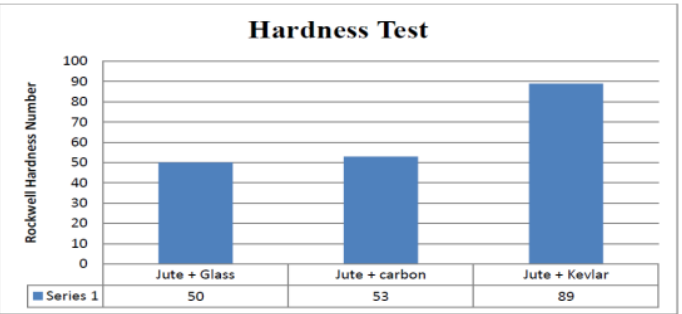

Influence of reinforcement and matrix material results in improve in hardness of Jute and Kevlar with epoxy resin compare to Jute-carbon and Jute -glass materials. From the table 2 and graph it is obvious that Jute- Kevlar -Epoxy laminate prove more Rockwell Hardness number than the other two materials

3.2 Comparison of Impact test Results of Jute-Glass-Epoxy, Jute-Kevlar-Epoxy and Jute-Carbon-Epoxy laminate composites

Table 3: Test results of Impact test

\begin{tabular}{|c|c|c|c|c|}
\hline $\begin{array}{c}\text { Sl. } \\
\text { No }\end{array}$ & Material & Trails & $\begin{array}{c}\text { Impact } \\
\text { Strength in } \\
\text { Joules }\end{array}$ & $\begin{array}{c}\text { Average } \\
\text { Impact } \\
\text { Strength in } \\
\text { Joules }\end{array}$ \\
\hline \multirow{2}{*}{1} & J-G-E & 1 & 3.40 & \\
& & 3 & 4.00 & 3.8 \\
\hline & & 1 & 4.00 & \\
& J-C-E & 2 & 5.46 & 5.46 \\
3 & & 3 & 5.40 & \\
& J-K-E & 2 & 10.00 & 9.6 \\
\hline
\end{tabular}
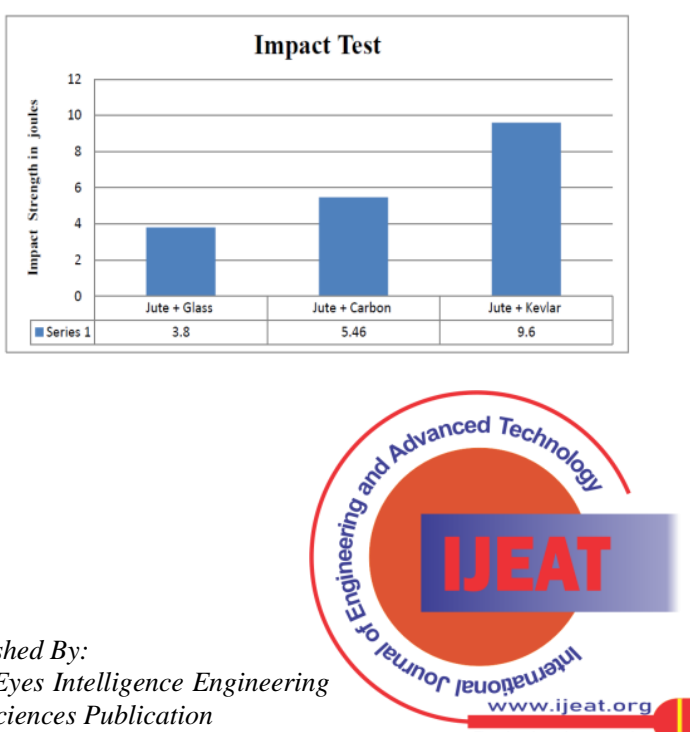
High molecular bonding between the Jute and Kevlar with epoxy resin results in improves in the hardness compare to Jute-carbon and Jute -glass materials. From the table 3 and graph it is obvious that Jute-Kevlar -Epoxy laminate having $3 \mathrm{~mm}$ thickness prove more impact strength than the other two materials

3.3 Comparison of Machinability test Results of Jute-Glass-Epoxy, Jute-Kevlar-Epoxy and Jute-Carbon-Epoxy laminate composites

Table: 4 Machinability test results

\begin{tabular}{|c|c|c|c|c|c|c|}
\hline \multirow{2}{*}{\begin{tabular}{c} 
MATERIA \\
\cline { 2 - 7 } L
\end{tabular}} & \multicolumn{5}{|c|}{$\mathbf{5 9 0}$} & \multicolumn{2}{|c|}{$\mathbf{9 9 0}$} & \multicolumn{2}{c|}{$\mathbf{1 7 2 5}$} \\
\cline { 2 - 7 } & $\begin{array}{r}\text { Torque } \\
\text { N-m }\end{array}$ & $\begin{array}{c}\text { Thrust } \\
\text { N }\end{array}$ & $\begin{array}{c}\text { Torqu } \\
\text { e } \\
\text { N-m }\end{array}$ & $\begin{array}{c}\text { Thrust } \\
\text { N }\end{array}$ & $\begin{array}{c}\text { Torqu } \\
\text { e } \\
\text { N-m }\end{array}$ & $\begin{array}{c}\text { Thrust } \\
\text { N }\end{array}$ \\
\hline J/G/E & 68.67 & 127.4 & 64.74 & 147.1 & 44.14 & 98.1 \\
\hline J/C/E & 75.53 & 176.5 & 68.67 & 156.9 & 62.74 & 117.7 \\
\hline J/K/E & 107.9 & 254.9 & 71.61 & 215.7 & 69.65 & 166.7 \\
& 1 & & & & & \\
\hline
\end{tabular}
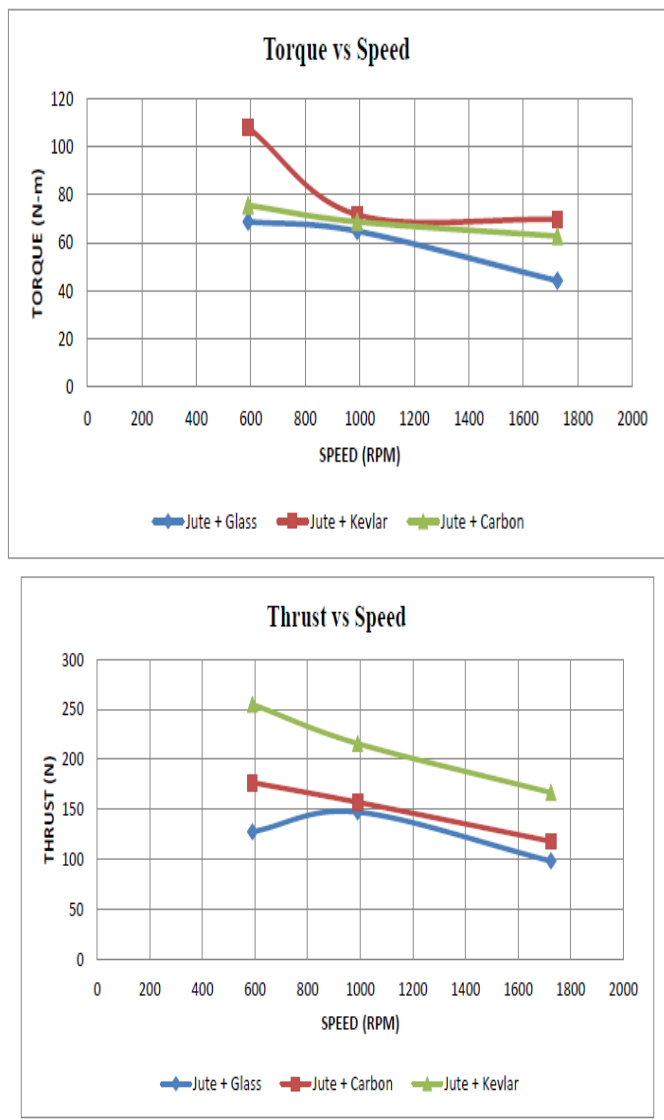

\section{Graph 1: Machinablity test results}

From the above table 4 and graph it is clear that by increasing spindle speed and feed rate results in the less thrust and torque in Jute-Glass-Epoxy, Jute-Carbon-Epoxy laminates and also it leads to maximum machining damages on machined surface compared to Jute-Kevlar-Epoxy laminates 3.4 Impact test SEM analysis of hybrid fiber

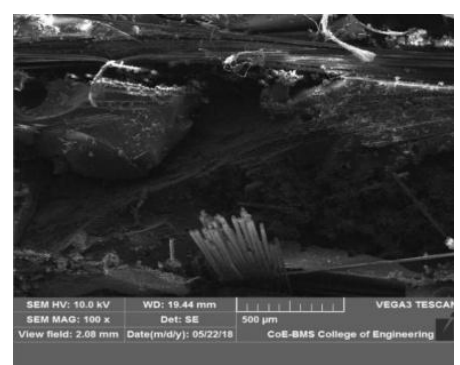

Figure 5(i)
Figure 5(ii)
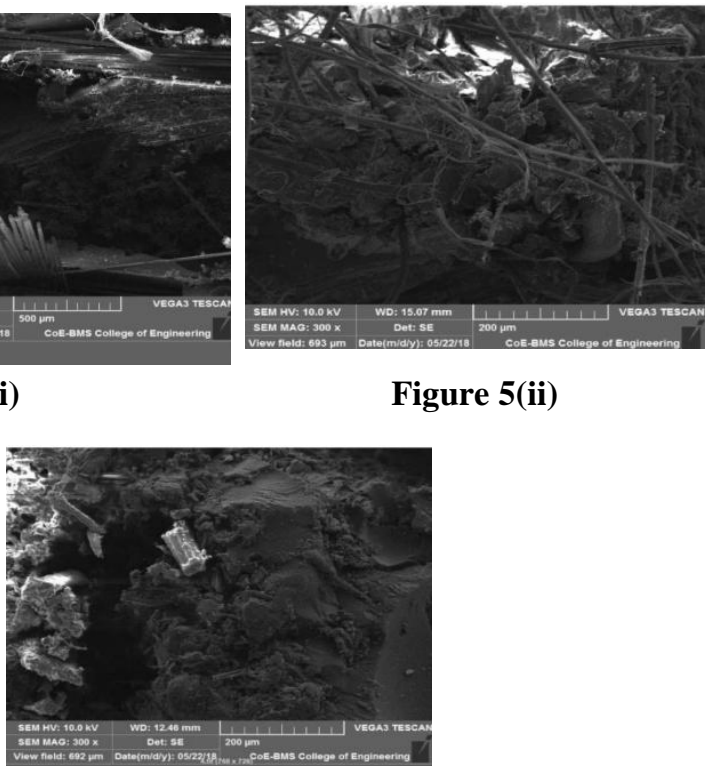

Figure 5(iii)

Fig 5(i,ii,iii) : Impact test SEM photograph of Jute /glass, Jute/carbon and Jute/Kevlar fiber

The SEM photograph of cracked surface of hybrid fiber reinforced composites. The impact crack is characterized by the brittle rupture with the accessibility of the voids, Fabric crack and fabric pull-out is evidence from the picture. The strict matrix deformation was demonstrated by the picture. The consciousness of fabric pull-out from the matrix is high. Fig 5(iii) demonstrate the efficient bonding sandwiched between the fabrics and the matrix, Hence the impact strength is more in Jute-Kevlar-Epoxy laminate composites compare to other two laminate composites

\subsection{Machinability test SEM analysis of hybrid fiber}
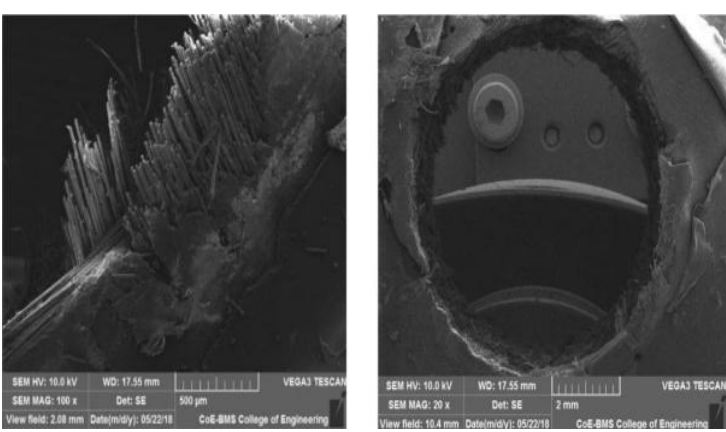

Figure 6(i)
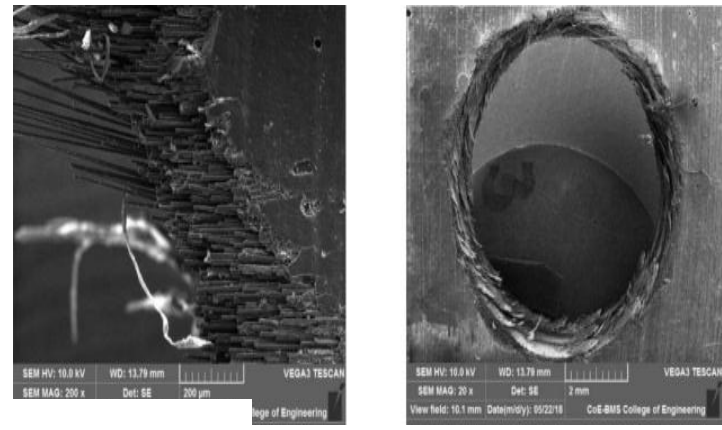

Figure 6(ii)

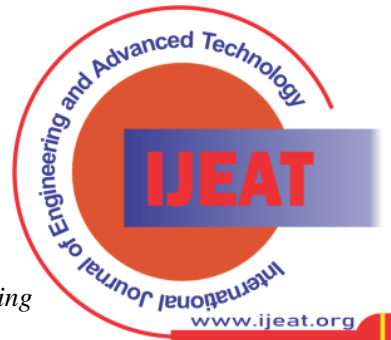
Exploring Innovation 

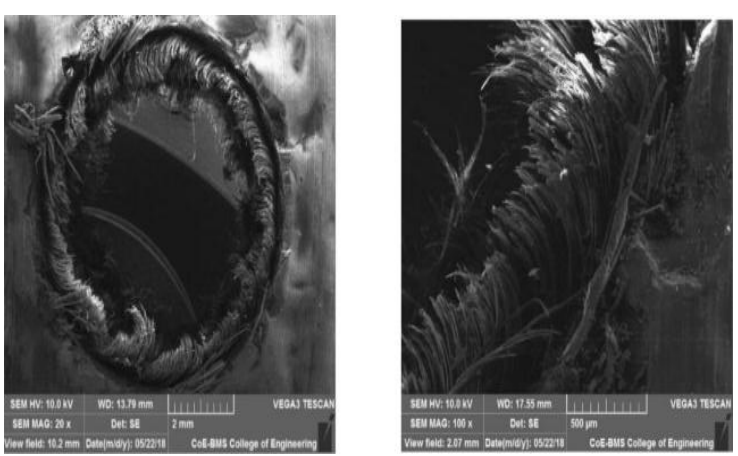

Figure 6(iii)

Fig 6(i,ii,iii): Machinability test SEM photograph of Jute-glass, Jute-carbon and Jute-Kevlar fabric

Composites indication of fabric drag out and unclear area of fabrics is the suggestion of the failure modes. Fig. 6(ii) shows the suggestion of hard surface cutting of fabrics and matrix cracking. This is to be expected produced where the machined work piece have more fabric angle ply. At this phase, the progress of stylus tip of the surface roughness measurer shows the maximum surface roughness values. Thus, the result of improved spindle speed and feed rate consequences the maximum machining damages on machined surface. Hence the withstanding thrust force will be more in jute/Kevlar/epoxy laminate composites compare to other two.

\section{CONCLUSIONS}

Specimens with constant thickness of $3 \mathrm{~mm}$ laminates are fabricated by hand layup technique followed by vacuum bagging, and test specimens have been prepared in accordance with the ASTM standards. In the hardness test nearly $46 \%$ hardness is greater in Jute Kevlar composite compare to other two composites. In Impact test nearly $60 \%$ impact strength is grater in Jute Kevlar composite compare to other two composites, and in machinability tests the torque and thrust force required is more in Jute Kevlar composite compare to other two composites. Hence, from the overall testing's it's clear that Jute Kevlar composite have more hardness, impact strength and machinability because of good characteristics and properties compare to Jute Glass and Jute carbon composites.

\section{REFERENCES}

1. Introduction to Composites and History of Composites, 2001 Composites, Volume 21 of ASM Handbook,

2. Andrzej K. Bledzki, Wenyang Zhang. Journal of Reinforced Plastics and Composites, 20 (2001) 1263-1274

3. C.V. Srinivasa, K.N. Bharath J. "Impact and Hardness Properties of Area Fabric-Epoxy Reinforced Composites" Mater. Environ. Sci. 2 (4) (2011) 351-356

4. Akhila Rajan, Jayalakshmi Gopinadha Kurup. Biochemical Engineering Journal, 25 (2005) 237-242

5. M. Ramesh and A. Gopinath "Measurement and analysis of thrust force in drilling sisal-glassfabric reinforced polymer composites" Materials Science and Engineering $197 \quad$ (2017) 012056 doi:10.1088/1757-899X/197/1/012056

6. Lokesh K.S, Dr.Thomas Pinto, Dr.Ramachandra C.G” Effect of Tool Wear \& Machinability Studies on Polymer Composites; a Review", International Journal of Engineering and Information Systems (IJEAIS) ISSN: 2000-000X.

7. Ravi kumar.M, Interlaminar Low-Velocity Impact Resistance of Hemp and E-Glass Hybrid Composite Laminates, Department of Mechanical Engineering, S.J.C.Institute of Technology, Chickaballpur, Karnataka, Vol. 3, Issue 7, July 2014
8. D. Ray, B.K. Sarkara, A.K. Rana, N.R. Bose "The mechanical properties of vinylester resin matrix composites reinforced with alkali-treated HempFibers" Part A 32 (2001) 119-12

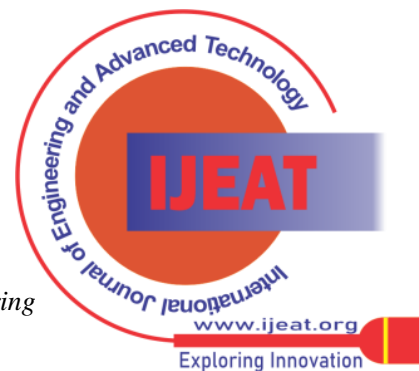

